\title{
Tolerance is Not Enough: The Moderating Role of Optimism on Perceptions of Regional Economic Performance
}

\author{
Miguel Pereira Lopes • Patricia Jardim da Palma • Miguel Pina e Cunha
}

Accepted: 21 July 2010/Published online: 4 August 2010

(C) Springer Science+Business Media B.V. 2010

\begin{abstract}
Current theories on economic growth are stressing the important role of creativity and innovation as a main driver of regional development. Some perspectives, like Richard Florida's 'creative class theory', have elected tolerance and diversity as a core concept in explaining differential development between different places, but his assumptions are challenged by other empirical and theoretical studies. In this article, we raise the possibility that tolerance is a necessary yet not a sufficient ingredient to trigger economic development in regions, and explore the role of subjective well-being (life-satisfaction, happiness, and optimism) as a moderator. Using a nationwide survey of 3,757 respondents from 21 different municipalities, the results show that optimism played the role of moderator, thus evidencing that psychological variables should be taken into account when trying to understand regional economic development.
\end{abstract}

Keywords Tolerance $\cdot$ Creative class $\cdot$ Optimism $\cdot$ Happiness $\cdot$ Life-satisfaction

\section{Introduction}

In recent years, economists have witnessed the emergence of a growing movement investigating the role of creativity in development and welfare. Interest in creativity as an engine of economic growth is not a novel issue. One could simply cite Schumpeter (1961) and his proposal of "creative destruction" to become aware of how important creativity is

M. P. Lopes $(\bowtie) \cdot$ M. P. e Cunha

Faculdade de Economia, Universidade Nova de Lisbon, Rua Marquês de Fronteira, 20, 1099-038 Lisbon, Portugal e-mail: mlopes@fe.unl.pt

M. P. e Cunha

e-mail: mpc@fe.unl.pt

P. J. da Palma

Instituto Superior de Psicologia Aplicada, Rua Jardim do Tabaco, 34,

1149-041 Lisbon, Portugal

e-mail: ppalma@ispa.pt 
for economic progress. But concern about the critical role of creativity in the economy has recently increased largely due to advances in the field of economic geography (e.g., Törnqvist 1983).

New concepts such as "creative cities" and "cultural industries" (Hall 2000) have contributed to a renewed curiosity for how creativity and other social processes help to explain economic growth or even dramatic paradigm shifts in societies and economies. Particularly popular today are the theoretical assumptions outlined by Florida (2002a) regarding the importance of creating a creative milieu to foster innovation and development. Florida's endeavor to understand what cities and regions can do to become more attractive to the "creative class" and to set the proper conditions to make creativity and innovation emerge with more propensity, is indeed compelling. In his view, creative human capital is a scarce resource and companies have to be persuasive as to how they can link themselves to these creative class individuals.

One visible output of this novel market reality, according to Florida (2002a, 2003), is that creative people are no longer running after a job, as used to happen in the industrial world. Instead, he found evidence that high-value hi-tech driven companies are now relocating to meet these creative individuals wherever they may be. Good examples are Yahoo, Google, and e-Bay, which settled down in certain places of the US (and abroad) according to the availability of these creative workers. This is so because the determinants for these workers to choose a place to live do not rely solely upon their wage. They value a variety of features in the environment where they live which allows them to express their creativity and to become innovative. But which features are these?

Based on a series of qualitative data (focus-group and interview) as well as quantitative data (mostly cross-sectional data), Florida (2004) concluded that creative workers prefer to live in places where there is a simultaneous presence of what he called the $3 \mathrm{Ts}$, namely technology, talent and tolerance. The main argument to explain the correlations between the 3Ts and economic development through innovation is that these environments allow for a multitude of information to recombine in new ways. Highly valued human capital with access to on-the-edge technology can certainly have access to higher levels of information. But the core of Florida's explanation is the tolerance T. Highly tolerant places set low barriers for whomever whishes to join and thus, by enhancing diversity, they strongly contribute to increased diverse knowledge and ideas, and consequently to more creativity and innovation (Florida 2002b).

Despite the enthusiasm with this perspective, however, Florida's assertions are not without their limitations, mostly because they seem to lack sound empirical support (Donegan et al. 2008) and have been questioned concerning their validity in cultural settings outside the United States (Asheim 2009). Asheim and Hansen (2009), for instance, have claimed that Richard Florida's work must be spatially and culturally situated. They found evidence that, due to differences in institutional factors such as social security policies, labor market composition, and the ease and need of mobility, the relationship between the 3Ts and economic development might not work in the same way in Europe as it does in the United States. No one would question the noteworthy economic growth through innovation of countries like Sweden, for example, although they rely more on in-house competence building and functional flexibility than on labor market mobility (Asheim 2009) and would thus not be cited by Florida as a case of a creative economy.

In line with these issues, Montgomery (2005) has also criticized the tight and limited criteria of Florida's perspective on the definition of what a creative city is. Montgomery asks methodological and statistical questions relating to the direction of causality in some of Florida's analysis, such as "are multi-ethnic societies of themselves more creative, or is 
it simply that employment and wealth creating opportunities attract all sorts of people to a dynamic economy?" (Montgomery 2005, p. 339). He also questions why, according to Florida's tolerance criteria, cities such as Barcelona and Helsinki, which are more conservative, are left out of the table despite their image of creativity and innovation. There must be something more to explain when and how creativity and innovation leads to higher economic growth.

In the words of Hospers (2003, p. 154) there seems to be "no recipe for cities to become creative in the knowledge economy" and, though some features such as tolerance, diversity, and human concentration seem to matter, other important aspects should be equated. In other words, it seems that the 3Ts are necessary but not sufficient factors to explain economic growth through innovation and, as such, there should exist important moderating variables that would help us to better understand when the 3Ts would lead to increased growth and when they would not.

In this way, the goal of this study is to examine the role of subjective well-being $(S W B)$ as a moderator of that relationship. Specifically, we investigate the moderating role of well-being, as measured by accounts of happiness, life-satisfaction and optimism, in the relationship between tolerance and perceptions of local economic performance. In other words, we expect that tolerance will lead to higher levels of perceived economic performance only when people experience high levels of SWB. When people instead experience low levels of SWB, living in a tolerant place should make no difference regarding economic performance evaluation.

Our reliance on SWB as a moderator variable is based on two main reasons. First, it seems logical that tolerance would work productively for economic development only as long as people feel they are well. Suppose a creative class worker lives in a tolerant, multiethnic, multi-cultural, diverse environment, with high levels of criminality and poor healthsupport facilities. Would he still prefer to work and live there? Would that kind of tolerance and diversity lead necessarily to a creative context in economic terms? This is one of the reasons why we believe that quality of life and SWB should be considered as a moderating variable. Montgomery (2005, p. 342) has asked a similar question and affirmed that "people also need to know that the city in question is convenient to live in and get around, that the schools are good, and that levels of crime and racial unrest are low. Otherwise, the attraction of certain cities to the 'creative class' will be short-lived".

Second, there is today an emerging but very considerable amount of evidence of the impact of well-being indicators on creativity, innovation, and economic growth. Empirical studies suggest that well-being positively impacts individual wage levels (Mohanty 2009a; Luthans et al. 2005, 2007), as well as the broader societal level (Diener 1984; Easterlin 2001a). Psychologists have long been interested in studying the conditions of creativity and innovation and have consistently found that the positive emotions associated with wellbeing are critical determinants of creative behavior (e.g., Fredrickson 2003). As such, one should expect that people become productively creative most of all when experiencing high levels of well-being.

For all these reasons, we deem as valuable our effort to better understand the moderating role of subjective well-being on the relationship between tolerance and economic performance. We do not oppose the creative class theory's assumption that tolerance and diversity promote economic welfare. Instead, our effort is focused on understanding when and how these relationships occur.

The rest of the article is organized as follows: first, we describe in better detail the creative capital theory and present further evidence of the importance of tolerance to explain innovation and economic growth. Next we develop our argument that well-being is critical for economic growth to occur and explicitly state the study hypotheses. We then present our 
data and the analysis we run to test the moderating hypothesis and end by discussing and stating the main conclusions and implications for future research on this issue.

\section{Theory and Hypothesis}

\subsection{Tolerance in Creative Capital Theory}

Creative class theory has become a high-profile topic in economic theory in the last years, mostly since the publication of Richard Florida's book Cities and the Creative Class (Florida 2004) where he extends his initial assumptions about the preferences of the creative class workers (Florida 2002a). The reasoning behind this theory unfolds according to a series of assumptions. First of all, the presence of the creative class workers (i.e., people who add economic value through their creativity) in a place leads to local creativity, which in turn affects regional economic development growth in the form of high levels of innovation and the expansion of technology-intensive sectors.

As such, a critical issue for the economic growth of a region is how much it can attract this creative kind of people and workers. These workers, argues Florida, will converge to places where certain "amenities" exist, despite real job opportunities. As stated by Storper and Scott (2009, p. 149), "the principal amenity said to act as a magnet for the creative class and to enhance creativity in general is tolerance". Florida's assumption is that tolerance is associated with low barriers to entry for recent immigrants, as it reduces the cultural conflicts and brings the best out of diversity (Florida 2004). Finally, as a result of the presence of creative people in any given place, there is a drive for creative interaction that positively affects regional economic growth at the city or regional level.

There are other place amenities that can also explain a place's attraction effect on the creative class, such as advanced communications technology or efficient urban transportation and mobility. But for Florida and his followers, tolerance seems to be the core amenity (Florida 2002b; Florida and Tinagli 2004). In fact, the rational can easily underlie the idea of an association between tolerance and creativity both directly and indirectly: directly, as it attracts the most creative people, given their supposed preferences for these kinds of places; indirectly, because by not erecting barriers to the entry of different people, there will be a diversity in several ways, including skill, ability, experiences, cognitive problem-solving styles, and cultural complementarity (Alesina and La Ferrara 2005; Hong and Page 1998).

This diversity should, ceteris paribus, contribute to an increased number of creative outputs given the probability for different informational combinations. Some have criticized Florida's work based on the distinction between creativity and innovation (Storper and Scott 2009). Because creativity and innovation constitute two different phenomena (Amabile 1996), and innovation but not creativity is the direct driver of economic growth, one should not assume a direct link between creativity and growth. However, because creativity represents the ability to solve problems in new ways and to produce novel outcomes from existing resources, it strongly relates to innovation (Lopes and Cunha 2009; Kerr and Gagliardi 2003), making Florida's argument compelling, although perhaps too simplistic and certainly not universally valid.

Given these considerations, the present study focuses on the critical role of tolerance as an amenity. We do not consider other amenities such as climate features (Glaeser and Tobio 2008) or entertainment attractions (Clark et al. 2002), as proposed by others. We also measure tolerance as a perceived variable to follow the same guidelines of Richard Florida, which relied on subjectively perceived evaluations of tolerance, defined as how 
many people living in a place accept and interact with people from other social groups (Florida and Tinagli 2004). In fact, this accords as well with to his perspective of tolerance as an intangible asset.

Given all this, we hypothesize that:

H1 Perceptions of tolerance positively influence the perceived economic performance of a region.

\subsection{Well-being in Economics}

The topic of well-being in economic theory is a relatively new one. It has risen in importance since economists became genuinely interested in understanding "real economics" and questioned the traditional views of the concepts of utility and preferences in the classical economic models (Frey and Stutzer 2002). The pioneering works of the Nobel Prize in economic sciences Daniel Kahneman and his colleagues, on the "noise" (i.e., biased behaviors and decisions) that classic economic theories failed to explain and his prospect theory (Tversky and Kahneman 1974; Kahneman and Tversky 1979), launched the bases to a new perspective on economic science.

Soon, researchers began to question if there exists a way other than that of revealed preferences (i.e., overt behavior) to take into account the preferences of economic agents, and started to measure well-being, life-satisfaction, and happiness as an alternative way to measure the utility of choices (Frey and Stutzer 2005; Kahneman et al. 1999). Subsequent research immediately demonstrated that these "subjective" measures of utility are robust and valid as indicators of true utility (Diener 1984; Veenhoven 1993). For example, researchers have found that happy people are rated as happy by friends and family members (Sandvik et al. 1993). This kind of evidence has led researchers to use well-being measures as good indicators of people's utility alongside more traditional measures such as GDP.

Given this, a series of investigations were run over the last years in order to better understand the relationships between SWB and traditional economic measures, such as money (Headey et al. 2008), and inflation and unemployment (Di Tella et al. 2001), among several others (for a good synthesis see Frey 2008). In general, these studies report significant and considerable relationships between SWB and economic variables, at least when researchers situate at a macroeconomic level (e.g., Easterlin 2001b). However, microeconomic and psychological explanations can help to understand why this happens at a macro level.

Mohanty (2009b), for instance, has recently found evidence that the positive attitude and happiness of individuals influences their individual wage. His results are in agreement with the results reported by other researchers, including those who advocate the wellknown thesis of the happy-productive worker (Wright and Staw 1999). In the same line, in the emerging field of positive organizational behavior, Luthans et al. $(2005,2007)$ have found that positive psychological capital (PsyCap), a measure of well-being including optimism and hope, positively impacts individual and organizational outputs, such as supervisor-rated performance, actual performance and job satisfaction.

This also seems to be true when considering aggregated larger samples of companies and entire industries. In a study investigating the well-being "virtues" of optimism, trust, and integrity of 710 respondents from 18 different companies, Cameron et al. (2004) found a significant influence of these variables on subjective and objective measures of organizational performance, including innovation, quality of output, and even profit margin. 
It is true that the main direction of influence between SWB and economic performance is not yet totally clear, but we have reasons to believe that SWB is an important driver of performance, from individual up to a more macro regional level. If happier, satisfied, and optimistic individuals seem to be more productive and improve their companies' innovation, quality, and profits, there should be a positive causal relationship between SWB and economic performance at the aggregate level.

As such, we hypothesize that:

H2 SWB positively influences the perceived economic performance of a region.

\subsection{Tolerance, Well-being, and Economic Performance}

As previously stated, all things being equal, tolerance at a regional level should positively impact economic growth, mostly driven by the higher diversity echelons that tolerant communities can attain. However, some authors have also equated higher diversity and tolerance with negative phenomena, such as a rise in conflict preferences. Rappaport (1999), for instance, has found that more racially fragmented cities in the US grow less in terms of population, a common variable used to measure development. In the same line, Alesina and La Ferrara (2000) found evidence that in US cities, individuals of different races are less willing to participate in social activities in racially mixed communities, undermining Florida's creative class theory assumption that tolerance and diversity necessarily bring a proactive collaboration between people from different groups.

In fact, this reluctance to cultural mixing can result from in-group bias (Tajfel and Turner 1986) and might actually explain why in more fragmented cities the provision of productive public goods (e.g., roads, hospitals, public schools) is quite lower (cf. Alesina et al. 1999) than in less fragmented cities, because one should be less available to provide taxes that favor out-group members, and that is the case where higher diversity levels exist. This actually means that a place's quality of life can in fact be, in some cases, threatened by higher diversity and cultural heterogeneity. This is particularly problematic for the supporters of the creative cities theories, because some authors have presented evidence showing that higher levels of quality of life are positively related to place attraction for most people.

Glaeser and Shapiro (2003), for instance, have concluded that crime rates explain the attraction-capability of a region. They analyzed population growth levels of several regions in the US and found that the population of northern and eastern regions of the country (known as the Rust Belt), such as Boston, declined in decades previous to 1980. Once crime rates started to decline in these northeastern cities after the 1980s, population started to rise again (particularly valuable human capital), partly returning from the Sunbelt cities of the south and southwest, such as Phoenix, Los Angeles, and San Francisco. It seems clear that there are some quality of life assets, such as low crime rates, that also figure into the equation for creative people to move onto another place. In the words of Storper and Scott (2009, p. 152), "the geography of urban growth depends ultimately on complex tradeoffs across a palette of amenities and consumer preferences, including climate, various dimensions of quality of life, housing costs and opportunities for wage-enhancing interaction".

All in all, these alternative views of what explains creative capital geographic mobility are not necessarily in disagreement with Florida's tenet that tolerance is important for attraction and effective functioning of creative workers and their last positive impact on the economy. But it evidences that his theory should be complemented by considering the quality of life and well being that citizens are offered in a place. In other words, tolerance should make a difference in explaining a regions' economic development, but this 
relationship should be moderated by the SWB levels that citizens feel in the place they live and work. As discussed above, happy, satisfied, and optimistic individuals should be able to make the best out of the diversity enabled by tolerance. On the contrary, people feeling unhappy, dissatisfied, or pessimistic about the future should miss the opportunity to profit from diversity.

As such, we specifically hypothesize that:

H3 SWB moderates the relationship between perceptions of tolerance and perceptions of economic performance in a way that this relationship will be stronger when SWB is higher.

\section{Data and Procedures}

\subsection{Sample}

The data were drawn from the 2009 edition of the "Great Municipalities to Live" initiative, which has run yearly in Portugal by INTEC - Behavioral Technology Institute since 2007. The initiative evaluates a series of quality of life indicators in ten domains, namely, housing, environment, health, education, economy and jobs, commuting, tourism, identity and leisure, tolerance and diversity, and happiness. Data rely on both quantitative indicators collected from official sources such as Eurostat, and qualitative indicators collected in a nationwide telephone survey with a total of 51 questions.

The 2009 edition considered in our data included 3,757 valid phone interviews (i.e., with no missing data) from 21 different municipalities from all over the country. The number of individuals surveyed per municipality ranged from 100 to 350 . To test our study's hypotheses, we relied on the qualitative data from the survey. The 3,757 respondents in the final sample were equally distributed in terms of gender, with $53.4 \%$ being female. In terms of age, $27.5 \%$ aged between 15 and 34 years, $33.6 \%$ between 35 and 54 years, and $38.9 \%$ percent between 55 and 74 years old. Data were collected between October and December 2008.

The indicators of tolerance, SWB, and economic performance were selected from the survey's questions according to their contribution to test our hypothesis. The five questions of the tolerance scale were selected from the survey's tolerance and diversity dimension, the three questions of the SWB scale-one regarding life-satisfaction, one happiness, and 1 optimism, were selected from the happiness dimension, and the single question of economic performance was selected from the economy and jobs dimension.

\subsection{Variable Measurement}

\subsubsection{Tolerance}

Tolerance was measured with a series of five questions concerning how much the citizens from the municipality deemed their fellows to be tolerant and good at integrating immigrants.

Tolerance Immigrants 1: Generally, what do your neighbors think about the coming of new immigrants to your municipality? For this item, the scale ranged from "Very Bad" (1) to "Very Good" (4). 
Tolerance Immigrants 2: Generally, how do you evaluate the way the immigrants are integrated in your municipality? For this item, the scale ranged from "Very Bad" (1) to "Very Good" (4).

Tolerance Immigrants 3: Comparing to the rest of the country, how tolerant are people that live in your municipality towards immigrants? For this item, the scale ranged from "Very Intolerant" (1) to "Very Tolerant" (4).

Tolerance Homosexuals: Comparing to the rest of the country, how tolerant are people that live in your municipality towards homosexuals? For this item, the scale ranged from "Very Intolerant" (1) to "Very Tolerant" (4).

Tolerance Religions: Comparing to the rest of the country, how tolerant are people that live in your municipality towards people from different religions? For this item, the scale ranged from "Very Intolerant" (1) to "Very Tolerant" (4).

\subsubsection{SWB}

The three dimensions of SWB were measured each with a single-item and a 4-point Likerttype rating scale. The questions for life-satisfaction, happiness, and optimism and their respective response options are:

Life-satisfaction: On the whole, how satisfied do you feel with your life these days? For this item, the scale ranged from "Very Dissatisfied" (1) to "Very Satisfied" (4). Happiness: Considering your life as a whole, how would you describe your happiness level? For this item, the scale ranged from "Very Unhappy" (1) to "Very Happy" (4).

Optimism: Generally, how optimistic have you been feeling towards the future? For this item, the scale ranged from "Very Pessimistic" (1) to "Very Optimistic" (4).

\subsubsection{Perceived Economic Performance}

This variable was measured with the following single-item question: Comparing to the rest of the country, how do you rate the economic performance of the municipality where you live? For this item, the scale ranged from "Very Poor" (1) to "Very Rich" (4).

\subsection{Analytic Strategy}

Before performing the moderation analysis necessary to test our hypotheses, we analyzed the structural validity and the reliability of our composite measures of tolerance and SWB. When evaluating the model's fit to the data we relied on both an index of absolute model fit (RMSEA: Root Mean Square of Error Approximation; Steiger 1990) and an index of relative model fit (CFI: Comparative Fit Index; Bentler 1990). According to the literature, values for the RMSEA are acceptable up to .08 and completely unacceptable above .10 . For CFI, a value of at least .90 has been proposed as necessary to consider an acceptable adjustment fit. In addition to these two kinds of model adjustment evaluation, there should also be an analysis regarding model parsimony. The most used parsimony fit measure is the $\chi^{2} /$ degrees of freedom ratio $\left(\chi^{2} / \mathrm{df}\right)$. For this ratio, values up to 2 are considered good (Hair et al. 1998). According to some authors, however, $\chi^{2} / \mathrm{df}$ values are considered unacceptable only above 5 (e.g., Klem 2000). 


\section{Results}

\subsection{Structural Validity and Reliability of Measures}

Because we measured tolerance with a multi-item scale, we started by analyzing the structural validity of this measure. First, we ran an exploratory factor analysis (EFA) with a principal component analysis. This analysis yielded a single-factor solution explaining an acceptable $55 \%$ of the total variance, $\mathrm{KMO}=.761$, Bartlett's sphericity test with a $p<.001$. To further investigate how robust the single-factor structure of the tolerance measure was, we also ran a confirmatory factor analysis (CFA). The single-factor model yielded acceptable indexes, with a $\chi^{2}(2,3757) / d f=5.6$, RMSEA $=.04, \mathrm{CFI}=.99$. We also tested the two-factor model, by separating the three items relating to immigrants with the other three items, but in this case the model yielded an unacceptable $\chi^{2}(2,3757) / d f$ fit index of 7.6. For this reason, we considered that we were measuring a single and comprehensive dimension of tolerance and proceeded accordingly in the remaining analysis.

We then analyzed the reliability of the dimension considered to measure tolerance by computing the Cronbach's Alpha, which yielded an acceptable value of .78. Because removing any of the items would lower the scale reliability, we decided to maintain all of them in computing the composite measure of tolerance. The composite measure of tolerance was then computed as the arithmetic mean of the values of the five items referring to tolerance.

As for the SWB measurement, we could not estimate a valid EFA, revealing that a onedimensional structure did not fit the data well. In addition, the computed Cronbach's Alpha including the three items of life satisfaction, happiness, and optimism, yielded a nonacceptable value of .59. As such, SWB was measured by considering the three items individually instead of considering a single overall construct.

Thus, life satisfaction, happiness, optimism, and perceived economic performance were all measured with a single-item scale. The measurement of these variables with a singleitem structure was constrained by the features of the available data, but the validity and reliability of these kinds of variables with a single-item option has been considered in economic literature to be as better as any other multi-item data (e.g., Frey and Stutzer 2002; Veenhoven 2000). As such, in the remaining analysis, we used these data as net values, without any transformation.

\subsection{Descriptive Results and Correlations}

Means, standard-deviations, and correlations between the variables are presented in Table 1. All correlations were statistically significant $(p<.01)$, and all were positive, as expected. The low correlation values rule out concerns for the potential existence of multicollinearity between the variables, with the exception of the correlation between lifesatisfaction and happiness $(r=.54)$. However, as these two variables were not regressed in the same models, this was not a problem for the present study.

\subsection{Hypothesis Tests}

Following Baron and Kenny (1986), we run a series of stepwise multiple regression analyses to test our moderation hypotheses (Table 2). We conducted separate analyses for life-satisfaction, happiness, and optimism, first introducing the predictor variable, then the 
Table 1 Means, standard-deviations, and correlations

\begin{tabular}{llllllll}
\hline & & Mean & SD & 1 & 2 & 3 & 4 \\
\hline 1. & Tolerance (1-4) & 2.33 & 0.74 & - & & & \\
2. & Life-satisfaction (1-4) & 2.97 & 0.64 & $0.14 * *$ & - & & \\
3. & Happiness (1-4) & 3.09 & 0.61 & $0.11^{* *}$ & $0.54 * *$ & - & \\
4. & Optimism (1-4) & 2.65 & 0.76 & $0.14 * *$ & $0.26 * *$ & $0.22^{* *}$ & - \\
5. & Perceived economic performance $(1-5)$ & 2.88 & 0.62 & $0.10^{* *}$ & $0.12 * *$ & $0.07 * *$ & $0.12^{* *}$ \\
\hline
\end{tabular}

$* p=.05 ; * * p=.01 ; * * * p=.001$

moderator variable, and finally the interaction variable. In all of the analyses, the criterion variable was perceived economic performance.

As expected in $\mathrm{H} 1$, the results evidence that tolerance has a significant direct impact on the perceived economic performance of the municipality when considered alone as a predictor $(\beta=.08 ; p<.001)$. In the same way, all three of the SWB variables have a significant marginal positive effect on perceived economic performance that goes beyond the effect of tolerance, both for life-satisfaction $(\beta=.104 ; p<.001)$, happiness $(\beta=.061 ; p<.001)$, and optimism $(\beta=.093 ; p<.001)$, confirming $\mathrm{H} 2$.

However, when entering the interaction variable for testing the study hypothesis we found a significant effect only for optimism. Specifically, we found no evidence for a moderator role of the interaction variable nor for tolerance $\times$ life-satisfaction $(\beta=.014$; n.s. $)$ or tolerance $\times$ happiness $(\beta=.022$; n.s.). On the contrary, for tolerance $\times$ optimism we found a full moderation effect on the relationship between tolerance and perceived economic performance $(\beta=.034 ; p<.05)$. In this case, when entering the interaction variable (tolerance $\times$ optimism), we found a significant increase in the model explaining variance $\left(\Delta R^{2}=.001\right.$; $p<.05$ ). Furthermore, the $\beta$ values of tolerance and optimism considered alone became nonsignificant ( $\beta=-.021$, n.s., and $\beta=.018$, n.s., respectively) when the interaction variable was introduced, showing a full moderation effect. We thus found evidence for partial support for hypothesis $\mathrm{H} 3$, namely concerning the optimism of people.

To interpret the nature of this interaction effect, we conducted additional analyses on the condition that seemed to strengthen the relationship between tolerance and perceived economic performance. We thus divided participants as being either high or low in optimism according to the variable mean $(X=2.64)$ and repeated this process for the tolerance variable $(X=2.31)$. We then ran an ANOVA to compare the groups in each of the interaction effects between optimism and tolerance (Fig. 1). The results evidence that the groups differ in terms of the level of passive coping with an $F(3,3648)=30.35, p<.001$.

The post-hoc analysis revealed that for optimistic individuals, regional economic performance was perceived as being higher when they were in a high tolerance context $(\mathrm{X}=2.98 ; \mathrm{SD}=.58)$ than when they were in a low tolerance context $(\mathrm{X}=2.85$; $\mathrm{SD}=.63), p<.001$. This was not the case for pessimistic individuals, for whom being in a high or low tolerance context made no difference $(\mathrm{X}=2.79$; $\mathrm{SD}=.64$ vs $\mathrm{X}=2.72$; $\mathrm{SD}=.66$, n.s.).

\section{Discussion}

A summary of our most significant results would state that the optimism of individuals does influence how much tolerance and diversity are used productively in economic terms. 


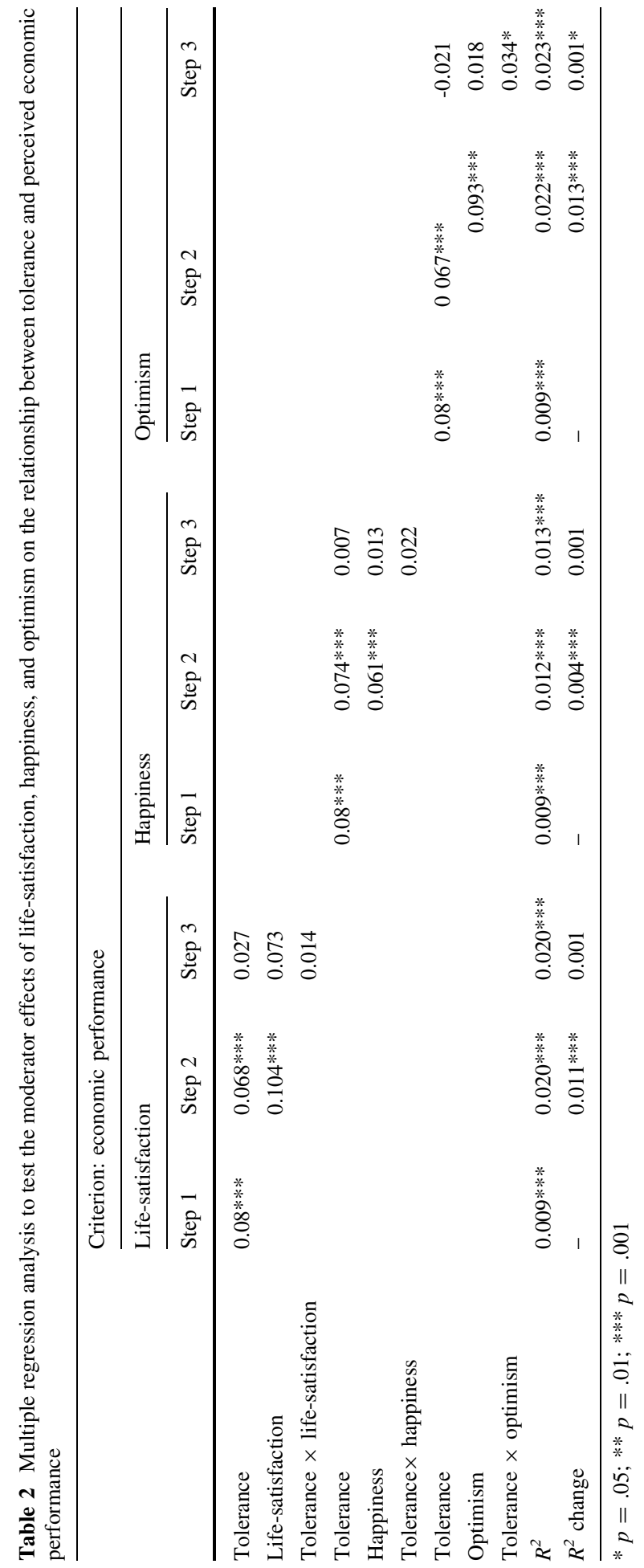




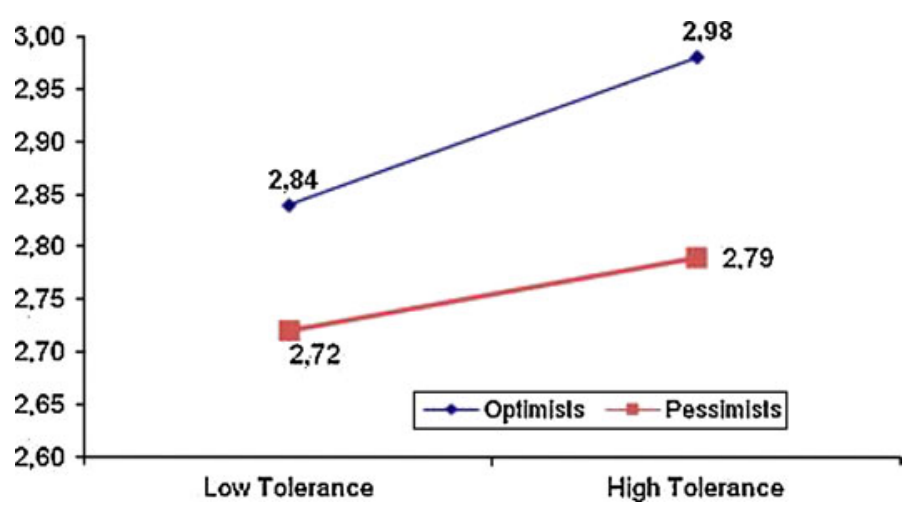

Fig. 1 Interaction effect between tolerance and optimism

On the contrary, we did not detect that moderator effect for the other two measures of wellbeing, neither for life-satisfaction, nor for happiness. This dissociation is important if we wish to understand when and how tolerance positively influences economic performance, as suggested in emergent theories of economic growth based on the creative class.

At first, our results point to a role of future expectations on the understanding of when tolerance positively influences economic performance. Prominent authors in the field of psychology and namely of positive psychology, notably Seligman and his colleagues (Peterson and Seligman 2003; Seligman 2002), have asserted that in a subjective realm, well-being includes the positive subjective experiences of individuals from their past (e.g., satisfaction and contentment), present (e.g., happiness, flow, ecstasy, and sensual pleasures), and future (e.g., optimism and hope). Our results thus support the idea that it is the future aspect of well-being, namely optimism, which plays an important role in the productive use of a place's tolerance and diversity.

Based on the extensive literature in psychology regarding optimism and its features, our results are not surprising. Scheier and Carver (1985) defined optimism as a generalized belief that good things will happen in the future. This positive expectation towards the future is related with positive outcomes such as higher achievement, increased perseverance, higher work motivation (Carver et al. 1993), and proactive behavior (Lopes and Cunha 2008; Aspinwall and Taylor 1997). Optimistic people are also more willing to proactively engage in activities that create business opportunities and entrepreneurial activity (Lopes et al. 2009; Becherer and Maurer 1999).

Brissette et al. (2002) also found evidence that optimistic people have friendship networks of a larger size, which can help to explain why optimists can contribute more in economic terms through creativity and innovation. Larger and more diverse social networks have been found to correlate positively with organizational performance (Borgatti and Foster 2003), creativity (Perry-Smith and Shalley 2003), and innovation (Miettinen 2006), thus supporting the idea that tolerant places should provide usable and combinable resources to promote innovation-based economic growth for those who are feeling optimistic (Florida 2002b).

We do not know why life-satisfaction and happiness did not moderate the relationship between tolerance and perceived economic performance, as did optimism. For happiness, a possibility is that people end up by adapting to their quality of life conditions and thus their happiness levels vary little or nothing (Oswald and Powdthavee 2008). Research in social 
psychology has shown that people can adapt quickly to both extremely positive and extremely negative events, evidencing that happiness is a relative phenomenon (Brickman et al. 1978). This adaptation effect has also been verified regarding economic issues. Some researchers have found evidence that income expectancies increase along with people's income aspirations and thus, their relative happiness remains generally the same (Van Herwaarden et al. 1977). The well known "Easterlin paradox" might well apply here. As found initially by Richard Easterlin (Easterlin 1995) and other researchers on happiness, cross-country comparisons of happiness and economic growth (as measured by GDP per capita) have empirically indicated that while GDP has increased substantially, happiness levels have remained unchanged.

As for life-satisfaction, often considered to be an indicator of happiness, the same reasoning applies. In addition, as life-satisfaction is based on an evaluation of one's past experiences and conditions, people might rationalize in order to reduce cognitive dissonance, a very well known and robust mental process studied in psychology for many years (Festinger 1957). On the whole, the idea that happiness and life-satisfaction are more stable and less diversified well-being measures due to psychological adaptation processes is a possibility to explain our differential results, an interpretation that is reinforced by statistical results on the variability obtained in the results of the present study. As we can see in Table 1, the dispersion measure (standard deviation) was much lower for happiness $(\mathrm{SD}=.61)$ and life-satisfaction $(\mathrm{SD}=.64)$ than for optimism $(\mathrm{SD}=.76)$.

Given these results, the next question would be to focus on how to promote optimism along with tolerance. As our results show, this is not always the case, and optimists are those who can profit the most from a tolerant and diverse environment in economic terms. Happily, based on previous theory on optimism, we do know something about how to promote these positive psychological expectations.

Some authors argue that these positive outcome expectancies are dependent on the way people explain the causes of negative events (Peterson and Chang 2003). Optimists tend to focus on external, unstable, and changeable specific causes to explain the occurrence of negative events. In the opposite, pessimists tend to focus on internal, stable, and fixed global/diffuse causes. Optimists thus tend to believe that their context is mutable and that they can do something to change it and to attain their goals (Carver and Scheier 1982). In addition, as found by Scheier et al. (1986), active behavior is particularly visible when optimists perceive their environment as controllable whereas when problems are perceived as uncontrollable, optimists have been found to disengage from active problem-solving and accept the situation more passively.

These conditions for optimism enhancement actually seem to support other assumptions of Florida's theory of creative cities, namely the other two Ts of technology and talent. A rich information environment made possible by a high-tech (particularly in IT) environment might better provide the controllable context in which optimism might flourish. In the same line, more talented people might also find their context as controllable and worthy of their efforts, because they have the skills to use it for their own goals.

However, other factor might help to create the necessary environment for optimism to thrive. In recent years, positive approaches to leadership have come to appear by stressing the role of leaders as promoters of higher positive psychological capabilities, such as optimism, in their followers (Avolio and Luthans 2006). In line with this, several authors have acknowledged that a major factor affecting positive expectations as optimism in people is leadership (Gardner and Schermerhorn 2004; Hollenbeck and Hall 2004).

Specifically, authentic leadership provides stronger insight about how to promote positive outcomes in a workforce (Gardner and Schermerhorn 2004; Luthans and Avolio 
2003). Authentic leadership is "a process that draws from both positive psychological capacities and a highly developed organizational context, which results in both greater selfregulated positive behaviour on the part of leaders and associates, fostering positive selfdevelopment" (Luthans and Avolio 2003, p. 243). Research has evidenced that a leader's support of this kind leads to positive outcomes both for people (e.g., job satisfaction, positive mood) and for companies (e.g., commitment, reductions in withdrawal behavior, performance) (Gardner and Schermerhorn 2004).

In the same way, Cameron (2008) has recently defined positive leadership as "the ways in which leaders enable positively deviant performance, foster an affirmative orientation in organizations, and engender a focus on virtuousness" (p. 8). This is quite in line with what was stated by Hospers (2003, p. 156) regarding the development of creative cities. He said that, "the successful development of creative cities depends upon clear vision, collaboration, attention for practical details". Thus, the psychosocial processes underlying positive leadership, at the organizational, regional, or political level should be worthy of investment in research if we want to design good theories of regional economic growth though creativity and innovation.

\section{Conclusions, Limitations and Implications}

This study sought to highlight the need to investigate when and how social tolerance positively impacts the economic performance of regions. Recent research on regional development has stressed that tolerance is a main cause of economic growth, but this does not seem to always be the case, pointing to the existence of moderators as complementary explanations. We found that the psychological variable of optimism adds potential value to explain when and how tolerance is a plus in enhancing economic performance. When people are optimistic they gather the opportunities to explore the higher diversity of available resources. When people are feeling pessimistic, much to the contrary, they do not grasp the opportunities of living and working in a tolerant and diverse place and do not profit from them. In these cases, tolerance is not an asset for the economy, and other political and managerial measures should be considered.

Despite the contributions of this study, we find some limitations that deserve reflection. First, we worked with a sample of a single country which might reduce the generalizability of our findings. It is true that working with data from a single country is very common, particularly in the case of the US. Working with data from a single country also has several advantages, such as controlling for cultural, political, linguistic, and other relevant intercountry differences. This is particularly true when testing theoretical hypotheses such as ours. However, research should further start to test moderation hypotheses concerning the relationship between tolerance and economic performance using multi-country databases. This will both test the generalizability of findings such as those of this paper as well as contribute to an in-depth knowledge about the role of psychological issues on these matters.

Second, we used only perceived indicators in the present study. Although this has the advantage of relying on the very same methodology to measure tolerance and well-being as that of authors from the creative class theory and those from happiness studies (thus making our results more comparable), considering more objective data would be a plus to better inform us of the whole picture. Further research on this topic should also use objective data, namely that regarding economic performance. 
Third, our dataset did not allow for a valid multi-level analysis because our first-order variable would be too small (i.e., 21 municipalities). However, future studies should be encouraged to investigate these issues. For example, are optimists the main type of person responsible for the better economic performance of the regions they inhabit, or is their optimism the consequence of living and working in a high performing economy? The data we used asked for respondents to evaluate the economic performance of their municipality but not their own economic performance. It is true that this was not directly relevant for the test of our hypotheses, but nevertheless, these are interesting questions waiting for additional research.

To finalize, we would like to pinpoint some implications of our findings to both theory and practice. For those who study regional development and economic growth, studying the role of psychological variables might prove to be fruitful research. Likewise, there is a vast area of studies for psychologists who would like to help increase our understanding of regional economic development dynamics. This study is only one example for this opportunity.

Our findings can also be valuable to practitioners, particularly for policy-makers and regional and local managers wishing to develop their creative places and advanced economic hubs. Sometimes too early excited with the fashionable idea of the "creative city", they run the risk of forgeting other critical determinants of positive economic growth. As our results indicate, however, regional managers should consider well-being and environmental issues (i.e., more controllable and transparent environments) beyond simply trying to attract people to a "melting pot" that can become too crowded and have a low quality of life, which will prove to be unsustainable (Donegan et al. 2008).

In sum, our results show that tolerance is not enough to explain economic development based on creative class theory's assumptions. Psychological concepts such as the optimism of individuals are critical to seize the opportunities made available by tolerance and diversity. Psychosocial processes such as positive and visionary leadership might also prove to be a necessary ingredient to promote the necessary positive expectation towards a future that will ultimately drive positive economic performance. These efforts will help us to understand when and how tolerance positively facilitates productive human behavior, and will ultimately help us to comprehend the psychosocial mechanisms beyond positive economic growth.

Acknowledgments The authors gratefully acknowledge the support of INTEC - Behavioral Technology Institute in making the data available for research purposes. We are also indebted to with Ana Monteiro for her help in managing the database.

\section{References}

Alesina, A., Baqir, R., \& Easterly, W. (1999). Public goods and ethnic divisions. Quarterly Journal of Economics, 114(4), 1243-1284.

Alesina, A., \& La Ferrara, E. (2000). Participation in heterogeneous communities. Quarterly Journal of Economics, 115(3), 847-904.

Alesina, A., \& La Ferrara, E. (2005). Ethnic diversity and economic performance. Journal of Economic Literature, 43(3), 762-800.

Amabile, T. M. (1996). Creativity in context. Boulder, CO: Westview Press.

Asheim, B. (2009). Introduction to the creative class in European city regions. Economic Geography, 85(4), $355-362$.

Asheim, B., \& Hansen, H. K. (2009). Knowledge bases, talents, and contexts: On the usefulness of the creative class approach in Sweden. Economic Geography, 85(4), 425-442. 
Aspinwall, L. G., \& Taylor, S. E. (1997). A stitch in time: Self-regulation and proactive coping. Psychological Bulletin, 121, 417-436.

Avolio, B. J., \& Luthans, F. (2006). The high impact leader: Moments matter in accelerating authentic leadership development. New York: McGraw-Hill.

Baron, R. M., \& Kenny, D. A. (1986). The moderator-mediator variable distinction in social psychological research: Conceptual, strategic, and statistical considerations. Journal of Personality and Social Psychology, 51, 1173-1182.

Becherer, R. C., \& Maurer, J. G. (1999). The proactive personality disposition and entrepreneurial behavior among small company presidents. Journal of Small Business Management, 38(1), 28-36.

Bentler, P. M. (1990). Comparative fit indexes in structural models. Psychological Bulletin, 107, $238-246$.

Borgatti, S. P., \& Foster, P. (2003). The network paradigm in organizational research: A review and typology. Journal of Management, 29(6), 991-1013.

Brickman, P., Coates, D., \& Janoff-Bulman, R. (1978). Lottery winners and accident victims: Is happiness relative? Journal of Personality and Social Psychology, 36, 917-927.

Brissette, I., Scheier, M. F., \& Carver, C. S. (2002). The role of optimism in social network development, coping, and psychological adjustment during a life-transition. Journal of Personality and Social Psychology, 82, 102-111.

Cameron, K. (2008). Positive leadership: Strategies for extraordinary performance. San Francisco: BerrettKoehler.

Cameron, K. S., Bright, D., \& Caza, A. (2004). Exploring the relationships between organizational virtuousness and performance. American Behavioral Scientist, 47, 766-790.

Carver, C. S., Pozo, C., Harris, S. D., Noriega, V., Scheier, M. F., Robinson, D. S., et al. (1993). How coping mediates the effect of optimism on distress: A study of women with early stage breast cancer. Journal of Personality and Social Psychology, 65, 375-390.

Carver, C., \& Scheier, M. F. (1982). Control theory: A useful conceptual framework for personality-social, clinical, and health psychology. Psychological Bulletin, 92, 111-135.

Clark, T. N., Lloyd, R., Wong, K. K., \& Jain, P. (2002). Amenities drive urban growth. Journal of Urban Affairs, 24, 493-515.

Di Tella, R., MacCulloch, R. J., \& Oswald, A. J. (2001). Preferences over inflation and unemployment: Evidence from surveys of happiness. American Economic Review, 91(1), 335-341.

Diener, E. (1984). Subjective well-being. Psychological Bulletin, 95, 542-575.

Donegan, M., Drucker, J., Goldstein, H., Lowe, N., \& Malizia, E. (2008). Which indicators explain metropolitan economic performance best? Journal of the American Planning Association, 74(2), 180-195.

Easterlin, R. (1995). Will raising the incomes of all increase the happiness of all? Journal of Economic Behavior and Organization, 27, 35-48.

Easterlin, R. A. (2001a). Income and happiness: Towards a unified theory. Economic Journal, 111, 465-484.

Easterlin, R. A. (2001b). Will raising the incomes of all increase the happiness of all? Journal of Economic Behavior \& Organization, 27(1), 35-48.

Festinger, L. (1957). A theory of cognitive dissonance. Stanford, CA: Stanford University Press.

Florida, R. (2002a). The rise of the creative class: And how it's transforming work, leisure, community and everyday life. New York: Basic Books.

Florida, R. (2002b). Bohemia and economic geography. Journal of Economic Geography, 2, 55-71.

Florida, R. (2003). Cities and the creative class. City \& Community, 2(1), 3-19.

Florida, R. (2004). Cities and the creative class. Routledge: New York.

Florida, R., \& Tinagli, I. (2004). Europe in the creative age. London: Demos Publication.

Fredrickson, B. L. (2003). The value of positive emotions: The emerging science of positive psychology is coming to understand why it's good to feel good. American Scientist, 91, 330-335.

Frey, B. S. (2008). Happiness: A revolution in economics. Cambridge: MIT Press.

Frey, B. S., \& Stutzer, A. (2002). What can economists learn from happiness research? Journal of Economic Literature, XL, 402-435.

Frey, B. S., \& Stutzer, A. (2005). Happiness research: State and prospects. Review of Social Economy, 63(2), 207-227.

Gardner, W. L., \& Schermerhorn, J. R. (2004). Unleashing Individual Potential: Performance gains through positive organizational behavior and authentic leadership. Organizational Dynamics, 33, 270-281.

Glaeser, E. L., \& Shapiro, J. (2003). Urban growth in the 1990s: is city living back? Journal of Regional Science, 43, 139-165.

Glaeser, E. L., \& Tobio, K. (2008). The rise of the sunbelt. Southern Economic Journal, 74(3), 610-643.

Hair, J. F., Anderson, R. E., Tatham, R. L., \& Black, W. C. (1998). Multivariate data analysis (5th Ed. ed.). London: Prentice-Hall. 
Hall, P. (2000). Creative cities and economic development. Urban Studies, 37(4), 639-649.

Headey, B., Muffels, R., \& Wooden, M. (2008). Money does not buy happiness: Or does it? A reassessment based on the combined effects of wealth, income and consumption. Social Indicators Research, 87(1), 65-82.

Hollenbeck, G. P., \& Hall, D. T. (2004). Self-confidence and leader performance. Organizational Dynamics, 33, 254-269.

Hong, L., \& Page, S.E. (1998). Diversity and optimality. Santa Fe Institute working paper 98-08-077.

Hospers, G. (2003). Creative cities: Breeding places in the knowledge economy. Knowledge, Technology \& Policy, 16(3), 143-162.

Kahneman, D., Diener, E., \& Schwarz, N. (Eds.). (1999). Well-being: The foundations of hedonic psychology. New York: Russell Sage Foundation.

Kahneman, D., \& Tversky, A. (1979). Prospect theory: An analysis of decisions under risk. Econometrica, 47, 313-327.

Kerr, B., \& Gagliardi, C. (2003). Measuring creativity in research and practice. In S. J. Lopez \& C. R. Snyder (Eds.), Positive psychological assessment: A handbook of models and measures (pp. 155-170). Washington, D.C.: American Psychological Association.

Klem, L. (2000). Structural equation modelling. In L. G. Grimm \& P. R. Yarnold (Eds.), Reading and understanding more multivariate statistics (pp. 227-259). Washington, DC: American Psychological Association.

Lopes, M. P., \& Cunha, M. P. (2008). Who is more proactive, the optimist or the pessimist? Exploring the role of hope as a moderator. Journal of Positive Psychology, 3(2), 100-109.

Lopes, M. P., \& Cunha, M. P. (2009). Innovation. In S. J. Lopez (Ed.), The encyclopedia of positive psychology (pp. 520-521). Boston: Blackwell Publishing.

Lopes, M. P., Cunha, M. P., \& Palma, P. J. (2009). Case studies on what entrepreneurs actually do to attract resources: A two-route framework. Journal of Enterprising Culture, 17(3), 323-349.

Luthans, F., \& Avolio, B. (2003). Authentic Leadership Development. In K. S. Cameron, J. E. Dutton, \& R. E. Quinn (Eds.), Positive organizational scholarship: Foundations of a new discipline (pp. 241-258). San Francisco: Berrett-Koeller.

Luthans, F., Avolio, B., Avey, J. B., \& Norman, S. M. (2007). Positive psychological capital: Measurement and relationship with performance and satisfaction. Personnel Psychology, 60, 541-562.

Luthans, F., Avolio, B., Walumba, F. O., \& Li, W. (2005). The psychological capital of Chinese workers: Exploring the relationship with performance. Management and Organization Review, 1(2), 247-269.

Miettinen, R. (2006). The sources of novelty: A cultural and systemic view of distributed creativity. Creativity and Innovation Management, 15(2), 173-181.

Mohanty, M. S. (2009a). Effects of positive attitude on earnings: Evidence from the US longitudinal data. Journal of Socio-Economics, 38(2), 357-371.

Mohanty, M. S. (2009b). Effects of positive attitude on happiness and wage: Evidence from the US data. Journal of Economic Psychology.

Montgomery, J. (2005). Beware 'the creative class': Creativity and wealth creation revisited. Local Economy, 20(4), 337-343.

Oswald, A. J., \& Powdthavee, N. (2008). Does happiness adapt? A longitudinal study of disability with implications for economists and judges. Journal of Public Economics, 92, 1061-1077.

Perry-Smith, J. E., \& Shalley, C. E. (2003). The social side of creativity: A static and dynamic social network perspective. Academy of Management Review, 28(1), 89-107.

Peterson, C., \& Chang, E. C. (2003). Optimism and flourishing. In C. Keyes \& J. Haidt (Eds.), Flourishing: Positive psychology and the life well-lived. Washington: American Psychological Association.

Peterson, C., \& Seligman, M. (2003). Positive Organizational Studies: Lessons from Positive Psychology. In K. S. Cameron, J. E. Dutton, \& R. E. Quinn (Eds.), Positive organizational scholarship: Foundations of a new discipline (pp. 14-27). San Francisco: Berrett Koehler.

Rappaport, J. (1999). Local growth empirics (p. 23). Harvard University: CID Working Paper.

Sandvik, E., Diener, E., \& Seidlitz, L. (1993). Subjective well-being: The convergence and stability of selfreport and non-self-report measures. Journal of Personality, 61(3), 317-342.

Scheier, M. F., \& Carver, C. S. (1985). Optimism, coping, and health: Assessment and implications of generalized outcome expectancies. Health Psychology, 4, 219-247.

Scheier, M. F., Weintraub, J. K., \& Carver, C. S. (1986). Coping with stress: Divergent strategies of optimists and pessimists. Journal of Personality and Social Psychology, 51, 1257-1264.

Schumpeter, J. (1961). The theory of economic development: An inquiry into capital, Credit, Interest and the Business Cycle. New York: Oxford University Press.

Seligman, M. (2002). Positive psychology, positive prevention, and positive therapy. In C. R. Snyder \& S. J. Lopez (Eds.), The handbook of positive psychology (pp. 3-12). New York: Oxford Press. 
Steiger, J. H. (1990). Structural model evaluation and modification : An interval estimation approach. Multivariate Behavioral Research, 25, 173-180.

Storper, M., \& Scott, A. J. (2009). Rethinking human capital, creativity and urban growth. Journal of Economic Geography, 9, 147-167.

Tajfel, H., \& Turner, J. C. (1986). The social identity theory of inter-group behavior. In S. Worchel \& L. W. Austin (Eds.), Psychology of intergroup relations. Chigago: Nelson-Hall.

Törnqvist, G. (1983). Creativity and the renewal of regional life. In A. Buttimer (Ed.), Creativity and context. Gleerup: Lund.

Tversky, A., \& Kahneman, D. (1974). Judgment under uncertainty: Heuristics and biases. Science, 185, 1124-1131.

Van Herwaarden, F., Kapteyn, A., \& Van Praag, B. (1977). Twelve thousand individual welfare functions: A comparison of six samples in Belgium and the Netherlands. European Economic Review, 9(3), 283-300.

Veenhoven, R. (1993). Happiness in nations: Subjective appreciation of life in 56 nations 1946-1992. Rotterdam: Erasmus University Press.

Veenhoven, R. (2000). Freedom and happiness: A comparative study in forty-four nations in the early 1990s. In Ed. Diener \& Eunkook. M. Suh (Eds.), Culture and subjective well-being (pp. 257-288). Cambridge, MA: MIT Press.

Wright, T. A., \& Staw, B. M. (1999). Affect and favorable work outcomes: Two longitudinal tests of the happy-productive worker thesis. Journal of Organizational Behavior, 20, 1-23. 